\title{
Sex and recombination in aflatoxigenic Aspergilli: global implications
}

\author{
Geromy G. Moore* \\ Southern Regional Research Center, Agricultural Research Service, United States Department of Agriculture, New Orleans, LA, USA
}

\section{Edited by:}

Perng-Kuang Chang, United States

Department of Agriculture, USA

\section{Reviewed by:}

Massimo Reverberi,

Sapienza - Università di Roma, Italy

Edwin Rene Palencia, United States

Department of Agriculture, USA

\section{${ }^{*}$ Correspondence:}

Geromy G. Moore, Southern Regional Research Center, Agricultural

Research Service, United States Department of Agriculture, 1100

Robert E. Lee Blvd, New Orleans, LA 70124, USA

e-mail: geromy.moore@ars.usda.gov

For most of the half century that aflatoxigenic species have been intensively studied, these molds were known only to reproduce asexually, with parasexuality found only in the laboratory between certain mutant strains. Therefore, the fairly recent discovery of their sexual (teleomorphic) states creates a new wrinkle in our understanding of the field behavior of these agriculturally significant fungi. Sex within populations of these fungi, and attendant genetic recombination, eventually may create difficulties for their control; and subsequently for the protection of important human and animal food supplies. Moreover, if fungal sex is a form of response to ecological and environmental stressors, then perhaps human influence and climate change could accelerate this phenomenon. This article will explore scientific research into sexuality and recombination in aflatoxigenic Aspergillus species; the potential impacts these phenomena could have on a popular method of preharvest prevention of aflatoxin contamination (i.e., use of non-aflatoxigenic $A$. flavus for biocontrol); and the outlook for maintaining control of aflatoxin contamination in an era of changing global climate.

\section{Keywords: Aspergillus, aflatoxin, sexuality, recombination, climate change, biocontrol}

\section{INTRODUCTION}

Within the expansive community of agriculturally significant fungi are species that pose health risks to animals and humans through the production of mycotoxins; consequently, these mycotoxigenic fungi are important to understand and to control (Bennett and Klich, 2003). Aflatoxins are the most serious agricultural mycotoxins. They are mostly produced by a group of fungal species within the genus Aspergillus' section Flavi (Bennett, 2010), although a few other species outside of this section produce aflatoxins, and carry homologs of the genes for aflatoxin (AF) synthesis (Bradshaw, 2006; Cary etal., 2009; Bradshaw et al., 2013). Aspergillus flavus and A. parasiticus are the most prominent aflatoxigenic $(\mathrm{AF}+)$ species with agricultural significance, contaminating cereal and oilseed crops as well as tree nuts; $A$. nomius has also been reported in agricultural fields (Feibelman et al., 1998; Ehrlich et al., 2007). The global economic losses due to contamination by these fungi are in the billions of dollars ( $\mathrm{Wu}$ et al., 2008). AF contamination causes negative impacts on health and life across the globe, especially in many developing nations where inhabitants lack the education regarding the risks of consuming aflatoxin-contaminated foods, lack understanding of the importance for proper food storage, or perhaps would rather risk eating contaminated crops than go hungry (Williams et al., 2004; Shephard, 2008). The burden of illness and death associated with aflatoxin consumption is a constant reminder that efficient AF control measures are in need of globalization.

Researchers are working to develop a food supply that is free of AF contamination through implementation of pre-harvest and/or post-harvest strategies (Hell et al., 2008; Abbas et al., 2011). One of the most appealing control measures involves the use of naturally occurring, non-aflatoxigenic ( $\mathrm{AF}-$ ) A. flavus as pre-harvest biological control instead of chemical fungicides. This method involves the field dispersal of a high volume of inocula composed of a highly competitive AF- strain. The presence of the AFstrains interferes with the proliferation of indigenous $\mathrm{AF}+$ fungi (Abbas et al., 2011). Studies on the genetic background of these $\mathrm{AF}$ - strains show that they result from either random mutations in, or absence/loss of, genes necessary for $\mathrm{AF}$ synthesis (Ehrlich and Cotty, 2004; Chang et al., 2005; Moore et al., 2009). Since their introduction a decade ago, two commercially available biopesticides have been in active use throughout the United States known as AF36 and Afla-Guard ${ }^{\circledR}$. Currently, other strains are being studied and developed as potential biocontrol agents, not only in the U.S. but also in other parts of the world (Pitt and Hocking, 2006; Abbas et al., 2011; Probst et al., 2011). This method of control is gaining favor due to its proven success at reducing AF contamination in the field, but our confidence in using $\mathrm{AF}-A$. flavus strains as biopesticides is based largely on the logic that they are predominantly asexual and genetically stable (Ehrlich and Cotty, 2004).

\section{RECOMBINATION AND SEXUALITY IN SECTION FLAVI}

Ken Papa explored parasexual recombination in A. flavus and A. parasiticus 40 years ago, but his findings were limited to laboratory experiments between mutant strains (Bennett, 1985). David Geiser was one of the first to report evidence for genetic recombination in A. flavus, due to a cryptic sexual state, and hence the potential risk for using A. flavus strains as biocontrol (Geiser et al., 1998). His findings inspired further studies by Ignazio Carbone's research group to uncover supportive evidence of recombination within the AF gene clusters of A. parasiticus and A. flavus populations sampled from within the same peanut field in the U.S. 
(Carbone et al., 2007; Moore et al., 2009). Recombination breakpoints within the AF gene clusters of $A$. parasiticus and A. flavus were observed, even though the $A$. parasiticus population exhibited less historical recombination compared to the A. flavus population in the same field (Moore et al., 2009). Moore et al. performed a global scale study of recombination for A. flavus and A. parasiticus field populations, representing five separate continents, and observed evidence of recombination within each A. flavus population examined and for two of the $A$. parasiticus populations (Moore et al., 2013a). Similar patterns of linkage disequilibrium (LD) could be observed for global $A$. flavus L-strain populations, although the same could not be observed for all of the sampled $A$. parasiticus or A. flavus S-strain populations. Ramirez-Prado et al. (2008) characterized mating alleles in A. flavus and A. parasiticus, and determined that since only one mating-type idiomorph (Mat1-1 or Mat1-2) could be amplified for each isolate it could be concluded that both species exhibit a heterothallic mating system. They developed a PCR diagnostic to quickly identify the idiomorphs, and using this diagnostic test they investigated the distribution of mating-types for the U.S. populations of A. flavus and $A$. parasiticus. Global recombination rates appear to correlate with the distribution of mating-type idiomorphs within certain field populations - an equal distribution of Mat1-1 and Mat12 will yield higher incidences of recombination as well as yield greater diversity of aflatoxigenicity among individuals (Moore et al., 2009). Recombination generates more individual offspring with genomes that differ from both parents, meaning that sex in fungi may increase the number of vegetative compatibility groups (VCGs; Olarte et al., 2011; Moore et al., 2013a). When fungi like $A$. flavus out-cross, they overcome barriers such as vegetative incompatibility (likely to prevent cell death) and allow the exchange of novel genetic material between two fertile strains (Pál et al., 2007; Horn et al., 2009a). Supportive evidence for this circumvention of vegetative incompatibility exists through mating studies in A. flavus and $A$. parasiticus whereby the only successful pairings involved strains from different VCGs and opposite mating types (Horn et al., 2009a,b).

Investigations into the sexuality of three AF+ species (A. parasiticus, $A$. flavus, and $A$. nomius) eventually led to the discovery and characterization of their teleomorph states using the taxonomic nomenclature of genus Petromyces (Horn et al., 2009a,b, 2011). The teleomorph discoveries for the AF+ Aspergilli occurred in the laboratory, and there are some who might argue that experimental crosses in a controlled environment are not representative of natural field conditions. However, experimental field studies by Horn et al. (2013) demonstrated A. flavus sexuality in the field. Ears of corn were inoculated with compatible parental strains and later found to contain sclerotia. The sclerotia harvested from the ears of corn were not cleistothecium-bearing stromata; however, sclerotia collected from the corn and further incubated in and on non-sterile soil eventually contained cleistothecia. Reportedly, when these sclerotia fall onto the soil out-crossing is stimulated (Horn et al., 2013). Another teleomorph discovery is the evidence of hybridization reported between $A$. flavus and A. parasiticus (Worthington etal., 2011). This may mean that the biological species recognition concept, which defines a species as reproductively isolated (Taylor et al., 2006;
Samson and Varga, 2009), cannot be applied to these aflatoxigenic Aspergilli.

A. flavus, A. nomius, and A. parasiticus exhibit self-incompatible (heterothallic) mating systems (Horn et al., 2009a,b, 2011). Of particular interest for $A$. nomius is that both mating-type idiomorphs may exist within a single strain, whereby certain isolates PCRamplified as both Mat1-1 and Mat1-2, and either idiomorph may be functional when out-crossing (Horn et al., 2011). A possible explanation for the presence of both mating-type idiomorphs may relate to the fact that Aspergillus species possess multi-nucleic conidiospores and hyphal cells, and are potentially heterokaryotic (Olarte etal., 2011; Runa et al., 2011). Olarte et al. (2011) examined progeny from out-crossing $A$. flavus strains that have either a full, partial, or absent AF gene cluster. In one generation of experimental crosses, most of the offspring exhibited recombinant genomes, having specific locus similarity to one or the other parent, while others were genetically distinct from both parents. They reported absence of cyclopiazonic acid (CPA) and AF loci in array Comparative Genomic Hybridization $(\mathrm{aCGH})$ analysis for progeny, despite both parents having full and present CPA and AF clusters within their genomes, and yet the loci could be amplified using PCR. They posit that cryptic alleles influence genome variability, since some offspring were observed to amplify portions of the CPA and AF clusters when both parents exhibited the partial/absent AF cluster configuration (Olarte etal., 2011). Olarte's research suggests that copy numbers of examined loci may influence the genomic condition observed, whereby low copy, ancestral alleles are often masked, but still present among heterokaryotic nuclei (Olarte et al., 2011).

\section{POTENTIAL IMPACTS OF SEXUAL RECOMBINATION ON $\boldsymbol{A}$. FLAVUS BIOCONTROL}

The effectiveness of pre-harvest biocontrol strategies using $\mathrm{AF}-\mathrm{A}$. flavus strains is based on their aggressiveness as competitors coupled with their inability to recombine with native AF+ strains, thereby preventing the re-acquisition of aflatoxigenicity (Ehrlich and Cotty, 2004; Abbas et al., 2011). Indeed, the biocontrol strains may be incapable of reinstated AF production, but not all of the offspring that result from their out-crossing will inherit the AF- phenotype. Through annual inundation of fields with biocontrol strains, the potential, over many generations, to increase the load of "super-competitors" with AF+ properties increases (Moore et al., 2013b). Given the possibility of obtaining multiple VCGs in a single generation, sexually promiscuous offspring could recombine with each other and further increase the population of AF+ individuals, thereby rendering the current biocontrol methodology ineffective in the future.

According to Olarte et al. (2011), the incidence of AF+ offspring observed was higher for crosses involving AF36 (58\%) than for the Afla-Guard strain ${ }^{\circledR}(36 \%)$. For offspring with an AF36 parent, replacement with a functional $p k s A$ gene can promote AF synthesis, but with the component strain in Afla-Guard ${ }^{\circledR}$ (NRRL 21882) lacking the entire AF gene cluster, a simple replacement is less likely. Since the re-acquisition of AF cluster genes in offspring is less likely, use of a biocontrol strain lacking cluster genes such as NRRL 21882 would be preferable to one with an 
intact AF gene cluster. There is never complete inheritance of the AF- phenotype in the offspring of a biocontrol parent, unless both parents exhibit partial- or absent-cluster genotypes (Olarte et al., 2011). In field populations where $\mathrm{AF}+$ strains are present, sex may yield toxigenic progeny. At this time, no studies have been reported that test colonization aggressiveness for progeny resulting from $\mathrm{AF}+$ and biocontrol strain pairings, though there is evidence that AF levels are not significantly higher in the offspring from these out-cross events (Olarte et al., 2011). However, Moore et al. (2013a) reported that higher incidences of toxin diversity exist in actively recombining populations of $A$. flavus and $A$. parasiticus. For example, balancing selection in $A$. flavus seeks to maintain the $\mathrm{AF}$ - phenotype, but active recombination will alter the overall AF load of the population by reducing the numbers of AF - individuals (Moore et al., 2009, 2013a).

With regard to hybridization between A. flavus and A. parasiticus, perhaps the impact from their recombination may be important to agriculture beyond their mycotoxigenic potential. Firstly, A. parasiticus is predominately a soil inhabitant (Angle et al., 1982), whereas A. flavus is more ubiquitous (ZuluagaMontero et al., 2010). Hybridization may allow A. parasiticus to alter or increase its niche through genetic modification. Hybrid offspring could exhibit far more diversity than recombinant offspring within each species (Olarte et al., 2011; Worthington et al., 2011). Perhaps, the most recently described AF+ "species" such as $A$. parvisclerotigenus and A. minisclerotigenes are actually hybrids, between $A$. flavus and $B+G$ AF producers such as A. parasiticus or A. nomius, which have persisted due to selective advantages resulting from their hybridization events. Current molecular techniques will allow us to refute or support this hypothesis.

In the future, when seeking to use $\mathrm{AF}-A$. flavus as pre-harvest biocontrol, there should be more diligence in researching the field ecology where biocontrol strain dispersal is intended for use or is currently in use. Specifically, the population density of native, potentially fertile AF+ species should be ascertained first by thorough field sampling; and additionally, the mating-type distribution of these native field strains should be determined since this will influence the stability of biocontrol (Moore et al., 2013a). If the field is predominately skewed to one mating type or the other, then using a biocontrol strain of the majority mating type could further restrict recombinant opportunities and slow the progression of both strain and toxin diversity (Moore et al., 2013a). In addition, any AF- strains sampled in a field should undergo extensive phenotypic and genomic investigations for consideration as biocontrol in the field where sampled (Moore et al., 2013a). Merely exhibiting the AF- phenotype is no longer a sufficient phenotypic criterion to warrant consideration of a strain as a candidate agent for biocontrol. Given its genotypic condition, the opportunity to generate AF+ offspring with a biocontrol strain such as NRRL 21882 is less likely than that with a strain such as AF36 (Olarte et al., 2011). Not only does NRRL 21882 exhibit the AF- phenotype because of it lacks AF cluster genes, but it also is incapable of producing CPA, another mycotoxin that is considered by some to have contributed to the severity of the Turkey X outbreak in the 1960s (Richard, 2008), while the AF36 biocontrol strain is AF- but produces CPA (Abbas et al.,
2011), and CPA production has been observed in all offspring resulting from out-crossing with the AF36 parent (Olarte et al., 2011).

\section{FUNGAL SEX AND RECOMBINATION IN A CHANGING GLOBAL CLIMATE}

There is increasing evidence that climate change is causing more unpredictability in global weather patterns. High heat and drought conditions stress plants and facilitate infection by aflatoxigenic species such as A. flavus (Scheidegger and Payne, 2003). Agricultural areas experiencing drought often suffer outbreaks of AF contamination. Moreover, diminished water availability limits the ability to irrigate and thereby mitigate the effects of drought (Kebede et al., 2012). At this time, incidences of AF outbreaks are most severe in tropical and sub-tropical areas (between latitudes $40^{\circ} \mathrm{N}$ and $40^{\circ} \mathrm{S}$ ) around the world (Williams et al., 2004), and even temperate regions such as the United States Midwest are subject to occurrences of AF contamination. However, if current scientific reports are accurate, the average global surface temperature has been increasing by $0.15^{\circ} \mathrm{F}$ each year since 1901 (United States Environmental Protection Agency [U.S.E.P.A], 2013). If temperatures continue to increase then the ideal climate for outbreaks of AF contamination will encompass more of our "temperate" agricultural regions and also become more frequent in occurrence. Therefore, it is imperative that as the research establishments continue to seek ways to control AF that researchers be aware of the potential impacts of climate change on the pathogenicity of AF+ fungi and the basic biology of these fungi. Sexual recombination often results from environmental stressors these fungi must overcome in order to adapt and survive. There is an extensive history of recombination in A. flavus (Moore et al., 2009). If global climate events assert constant negative pressures on AF+ Aspergilli, then this may accelerate the frequency of recombination in natural populations and lead to unfavorable outcomes for crop protection.

\section{CONCLUSION}

The ultimate goal for using AF-A. flavus as biocontrol agents is long-term crop protection. Although biocontrol strains are reported to persist for years in inoculated fields (Cotty, 2013), current strategies require annual re-application of biocontrol strains. If the signature of the biocontrol strain is lost then perhaps recombination is to blame. Potentially, even a low rate of recombination between native AF+ fungi and introduced $\mathrm{AF}-$ fungi is significant when one considers future food safety. Generations from now, the aflatoxin problem may become more intractable because of the short-term method currently being used to prevent pre-harvest contamination. These fungi are - and have long been - sexually active. Their ability to evolve new phenotypes and genotypes via sexual recombination is a fact that cannot be ignored.

Sometimes, pathologists refer to plant: pathogen interactions as an evolutionary arms race (Anderson et al., 2010). Perhaps the same could be said for the use of non-aflatoxigenic strains for aflatoxin control. Hopefully, with continued research and understanding, we can maintain a consistent level of control without future risk of exacerbating the aflatoxin problem. 


\section{REFERENCES}

Abbas, H. K., Zablotowicz, R. M., Horn, B. W., Phillips, N. A., Johnson, B. J., Jin, X., et al. (2011). Comparison of major biocontrol strains of non-aflatoxigenic Aspergillus flavus for the reduction of aflatoxins and cyclopiazonic acid in maize. Food Addit. Contam. A. 28, 198-208. doi: 10.1080/19440049.2010.544680

Anderson, J. P., Gleason, C. A., Foley, R. C., Thrall, P. H., Burdon, J. B., and Singh, K. B. (2010). Plants versus pathogens: an evolutionary arms race. Funct. Plant Biol. 37, 499-512. doi: 10.1071/FP09304

Angle, J. S., Dunn, K. A., and Wagner, G. H. (1982). Effect of cultural practices on the soil population of Aspergillus flavus and Aspergillus parasiticus. Soil Sci. Soc. Am. J. 46, 301-304. doi: 10.2136/sssaj1982.03615995004600020017x

Bennett, J. W. (1985). "Taxonomy of the fungi and biology of the Aspergilli," in Biology of Industrial Microorganisms, eds A. L. Demain and N. A. Solomon (Boston, MA: Addison-Wesley), 359-406.

Bennett, J. W., and Klich, M. A. (2003). Mycotoxins. Clin. Microbiol. Rev. 16, 497-516. doi: 10.1128/CMR.16.3.497-516.2003

Bennett, J. W. (2010). "An overview of the genus Aspergillus," in Aspergillus: Molecular Biology and Genomics, eds M. Machida and K. Gomi (Portland, OR: Caister Academic Press), 1-17.

Bradshaw, R. E. (2006). From protoplasts to gene clusters. Mycologist 20, 133-139. doi: 10.1016/j.mycol.2006.09.012

Bradshaw, R. E., Slot, J. C., Moore, G. G., Chettri, P., de Wit, P. J. G. M., Ehrlich, K. C., et al. (2013). Fragmentation of an aflatoxin-like gene cluster in a forest pathogen. New Phytologist 198, 525-535. doi: 10.1111/nph. 12161

Carbone, I., Jakobek, J. L., Ramirez-Prado, J. H., and Horn, B. W. (2007). Recombination, balancing selection and adaptive evolution in the aflatoxin gene cluster of Aspergillus parasiticus. Mol. Ecol. 16, 4401-4417. doi: 10.1111/j.1365294X.2007.03464.x

Cary, J. W., Ehrlich, K. C., Beltz, S. B., Harris-Coward, P., and Klich, M. A. (2009). Characterization of the Aspergillus ochraceoroseus aflatoxin/sterigmatocystin biosynthetic gene cluster. Mycologia 101, 352-362. doi: 10.3852/08-173

Chang, P.-K., Horn, B. W., and Dorner, J. W. (2005). Sequence breakpoints in the aflatoxin biosynthesis gene cluster and flanking regions in nonaflatoxigenic Aspergillus flavus isolates. Fungal Genet. Biol. 42, 914-923. doi: 10.1016/j.fgb.2005.07.004

Cotty, P. J. (2013). Frequently Asked Questions about AF36 on Cotton, FAQ - ARS Cotty Lab, The University of Arizona. Available at: http://ag.arizona.edu/research/cottylab/faq.htm\#seventeenth [accessed December 30, 2013]

Ehrlich, K. C., and Cotty, P. J. (2004). An isolate of Aspergillus flavus used to reduce aflatoxin contamination in cottonseed has a defective polyketide synthase gene. Appl. Microbiol. Biotechnol. 65, 473-478. doi: 10.1007/s00253-004-1670-y

Ehrlich, K. C., Kobbeman, K., Montalbano, B. G., and Cotty, P. J. (2007). Aflatoxinproducing Aspergillus species from Thailand. Int. J. Food Microbiol. 114, 153-159. doi: 10.1016/j.ijfoodmicro.2006.08.007

Feibelman, T. P., Cotty, P. J., Doster, M. A., and Michailides, T. J. (1998). A morphologically distinct strain of Aspergillus nomius. Mycologia 90, 618-623. doi: $10.2307 / 3761221$

Geiser, D. M., Pitt, J. I., and Taylor, J. W. (1998). Cryptic speciation and recombination in the aflatoxin-producing fungus Aspergillus flavus. Proc. Natl. Acad. Sci. U.S.A. 95, 388-393. doi: 10.1073/pnas.95.1.388

Hell, K., Fandohan, P., Bandyopadhyay, R., Kiewnick, S., Sikora, R., and Cotty, P. J. (2008). "Pre- and postharvest management of aflatoxin in maize: an African perspective," in Mycotoxins: Detection Methods, Management, Public Health and Agricultural Trade eds J. F. Leslie, R. Bandyopadhyay, and A. Visconti (Oxfordshire, UK: CAB International), 219-229.

Horn, B. W., Ramirez-Prado, J. H., and Carbone, I. (2009a). Sexual reproduction and recombination in the aflatoxin-producing fungus Aspergillus parasiticus. Fungal Genet. Biol. 46, 169-175. doi: 10.1016/j.fgb.2008.11.004

Horn, B. W., Moore, G. G., and Carbone, I. (2009b). Sexual reproduction in Aspergillus flavus. Mycologia 101, 423-429. doi: 10.3852/09-011

Horn, B. W., Moore, G. G., and Carbone, I. (2011). Sexual reproduction in aflatoxinproducing Aspergillus nomius. Mycologia 103, 174-183. doi: 10.3852/10-115

Horn, B. W., Sorensen, R., Lamb, M., Sobolev, V., Olarte, R., Worthington, C., et al. (2013). Sexual reproduction in Aspergillus flavus sclerotia naturally produced in corn. Phytopathology 104, 75-85. doi: 10.1094/PHYTO-05-130129-R
Kebede, H., Abbas, H. K., Fisher, D. K., and Bellaloui, N. (2012). Relationship between aflatoxin contamination and physiological responses of corn plants under drought and heat stress. Toxins 4, 1385-1403. doi: 10.3390/toxins4111385

Moore, G. G., Elliott, J. L., Singh, R., Dorner, J. W., Stone, E. A., Chulze, S. N., et al. (2013a). Sexuality generates diversity in the aflatoxin gene cluster: evidence on a global scale. PLoS Pathog. 9:e1003574. doi: 10.1371/journal.ppat.10 03574

Moore, G. G., Mack, B. M., and Beltz, S. B. (2013b). Testing the efficacy of eGFPtransformed Aspergillus flavus as biocontrol strains. Food Nutr. Sci. 4, 469-479. doi: 10.4236/fns.2013.44060

Moore, G. G., Singh, R., Horn, B. W., and Carbone, I. (2009). Recombination and lineage-specific gene loss in the aflatoxin gene cluster of Aspergillus flavus. Mol. Ecol. 18, 4870-4887. doi: 10.1111/j.1365-294X.2009.04414.x

Olarte, R. A., Horn, B. W., Dorner, J. W., Monacell, J. T., Singh, R., Stone, E. A., et al. (2011). Effect of sexual recombination on population diversity in aflatoxin production by Aspergillus flavus and evidence for cryptic heterokaryosis. Mol. Ecol. 21, 1453-1476. doi: 10.1111/j.1365-294X.2011.05398.x

Pál, K., van Diepeningen, A. D., Varga, J., Hoekstra, R. F., Dyer, P. S., and Debets, A. J. M. (2007). Sexual and vegetative compatibility genes in the Aspergilli. Stud. Mycol. 59, 19-30. doi: 10.3114/sim.2007.59.03

Pitt, J. I., and Hocking, A. D. (2006). Mycotoxins in Australia: biocontrol of aflatoxin in peanuts. Mycopathologia 162, 233-243. doi: 10.1007/s11046-006-0059-0

Probst, C., Bandyopadhyay, R., Price, L. E., and Cotty, P. J. (2011). Identification of atoxigenic Aspergillus flavus isolates to reduce aflatoxin contamination of maize in Kenya. Plant Dis. 95, 212-218. doi: 10.1094/PDIS-0610-0438

Ramirez-Prado, J. H., Moore, G. G., Horn, B. W., and Carbone, I. (2008). Characterization and population analysis of the mating-type genes in Aspergillus flavus and Aspergillus parasiticus. Fungal Genet. Biol. 45, 1292-1299. doi: 10.1016/j.fgb.2008.06.007

Richard, J. L. (2008). Discovery of aflatoxins and significant historical features. Toxin Rev. 27, 171-201. doi: 10.1080/15569540802462040

Runa, F., Carbone, I., and Payne, G. A. (2011). "Nuclear condition in Aspergillus flavus during growth and conidiation," in Genetics of Maize Disease Workshop, Raleigh. Available at: http://www.pngg.org/maize/abstract.html [accessed February 20-23, 2011].

Samson, R. A., and Varga, J. (2009). What is a species in Aspergillus? Medical Mycology 47 (S1), S13-S20. doi: 10.1080/13693780802354011

Scheidegger, K. A., and Payne, G. A. (2003). Unlocking the secrets behind secondary metabolism: a review of Aspergillus flavus from pathogenicity to functional genomics. Toxin Rev. 22, 423-459. doi: 10.1081/TXR-1200 24100

Shephard, G. S. (2008). Impact of mycotoxins on human health in developing countries. Food Addit. Contam. A. 25, 146-151. doi: 10.1080/02652030701567442 Taylor, J. W., Turner, E., Townsend, J. P., Dettman, J. R., and Jacobson, D. (2006). Eukaryotic microbes, species recognition and the geographic limits of species: examples from the kingdom Fungi. Philos. Trans. R. Soc. Lond. B Biol. Sci. 361, 1947-1963. doi: 10.1098/rstb.2006.1923

United States Environmental Protection Agency. [U.S.E.P.A]. (2013). "Climate Change Indicators in the United States" in EPA. Available at: http://www.epa.gov/climatechange/science/indicators/weather-climate/tempera ture.html [accessed Sepetember 20, 2013 and November 21, 2013].

Williams, J. H., Phillips, T. D., Jolly, P. E., Stiles, J. K., Jolly, C. M., and Aggarwal, D. (2004). Human aflatoxicosis in developing countries: a review of toxicology, exposure, potential health consequences, and interventions. Am. J. Clin. Nutr. 80, 1106-1122.

Worthington, C. J., Horn, B. W., Moore, G. G., Monacell, J. T., Singh, R., Stone, E. A., et al. (2011). "Hybridization between Aspergillus flavus and Aspergillus parasiticus," in Fungal Genetics Conference Proceedings, Pacific Grove, CA.

Wu, F., Liu, Y., and Bhatnagar, D. (2008). Cost-effectiveness of aflatoxin control methods: economic incentives. Toxin Rev. 27, 203-225. doi: $10.1080 / 15569540802393690$

Zuluaga-Montero, A., Ramírez-Camejo, L., Rauscher, J., and Bayman, P. (2010). Marine isolates of Aspergillus flavus: denizens of the deep or lost at sea? Fungal Ecol. 3, 386-391. doi: 10.1016/j.funeco.2010.05.003

Conflict of Interest Statement: The associate editor Perng-Kuang Chang declares that despite being in the same research area at the United States Department of 
Agriculture as the author Geromy Moore (Food and Feed Safety Research at Southern Regional Research Center), the review process was handled objectively and no conflict of interest exists.

Received: 16 December 2013; accepted: 17 January 2014; published online: 05 February 2014.

Citation: Moore GG (2014) Sex and recombination in aflatoxigenic Aspergilli: global implications. Front. Microbiol. 5:32. doi: 10.3389/fmicb.2014.00032
This article was submitted to Food Microbiology, a section of the journal Frontiers in Microbiology.

Copyright $($ ) 2014 Moore. This is an open-access article distributed under the terms of the Creative Commons Attribution License (CC BY). The use, distribution or reproduction in other forums is permitted, provided the original author(s) or licensor are credited and that the original publication in this journal is cited, in accordance with accepted academic practice. No use, distribution or reproduction is permitted which does not comply with these terms. 